\title{
Biodiversity in flames
}

\author{
Fires in Australia show the devastating interaction between climate and biodiversity emergencies, and make clear \\ that action is needed at all levels.
}

T he beginning of 2020, 'super year of biodiversity' and crunch year for climate negotiations, has brought a tragic demonstration of the interdependence of climate and biodiversity crises. The fires currently engulfing Australia are the largest known since the arrival of Europeans, and the summer fire season is still in its early stages. Fires burn and spread because of current weather conditions and because of the quantity, distribution and dryness of fuel, which are determined by interactions between climate and forest ecology. While limited fires can have positive consequences for biodiversity, the effect of those at the scale currently being experienced is catastrophic, both for species and for ecosystems.

This season has seen record-breaking temperatures in eastern Australia, which provide the conditions for fire ignition and spread. There is no doubt that such conditions will become more frequent and that new records will soon be set, and that this is the result of anthropogenic climate change. In addition, high temperatures and reduced precipitation in recent months and years have caused drought and a consequent build-up of suitably dry fuel. Fundamentally, a rapid reduction in global emissions is the only thing that will make a major difference to how frequent and widespread fires will be in the future.

This is where politics becomes the issue. The environment was a major part of the campaign in Australia's most recent election, and the coalition government that won has downplayed the link between emissions and warming, and has promoted the continuing use of fossil fuels. Although there has been widespread anger at the government's reaction to the fire crisis, it remains unclear whether this will be enough to enforce a change of policy direction. This anger has to work against the climate-change denialism that is still rife in sections of Australia's media and political establishment. There have therefore been attempts to deflect the blame away from climate towards arsonists or even environmentalists and their perceived hostility to fuel-reduction interventions.

This is not to say that ecosystem management does not play a role in mitigating fire risk. Disastrous fires are most likely to occur in areas with intermediate levels of human population ${ }^{1}$, implying that agricultural practices in particular could be important determinants of risk. There may also be a role for controlled burning to reduce risk; indeed, some Australian landscapes have been burnt on a small scale by Indigenous communities for tens of thousands of years, and there is much to be learnt from this kind of stewardship. The problem is that discussing now whether different strategies should have been applied before the fires started leads to a degree of confusion over timescales. What might have been appropriate then, will not help now, and may be a deliberate distraction from the failure of emissions policies. And perhaps more importantly, future climate projections mean that we will be living with conditions that are unprecedented, so great care is needed in extrapolating from strategies that may have worked previously.

In many previous fire crises around the globe, media attention has predominantly focused on loss of human life and property. This is entirely understandable, and the personal tragedies involved should in no way be downplayed. However, this time there has also been considerable attention given to the consequences for wildlife. Much of this has been focused on animals, and Australia's iconic marsupials in particular. The headline-grabbing figure that one billion animals have probably perished has certainly driven much of this coverage, but the loss of specific endangered species, particularly on Kangaroo Island, has also garnered attention. The one billion number is relatively easy for the media and public to digest, and thereby serves a good purpose, but it is not necessarily the metric of most relevance to ecologists. Even if we focus just on animals, we need to pay as much attention to endemism, migration and life history traits as to abundance.

However, it may be even more meaningful to focus on plants and whole ecosystems. Eucalypt-dominated forests in eastern Australia are, in normal circumstances, able to recover after fire, and some plant species actually require occasional burning. However, there is a worry that if the interval between incidents of fire-promoting weather is reduced, and also if fires consume larger sections of the landscape with fewer refugia, such recovery will not be possible. Eucalypt forest is also not the only type of ecosystem found in the region. While the only known natural grove of Wollemi pines has been saved at the time of writing, there have been substantial losses to areas of rainforest that would not normally experience fire and are not fire-adapted. Moisture levels in rainforest areas that co-exist in a matrix with eucalypt forest are usually sufficient to stop them burning, but prolonged drought, increased temperature, and the sheer extent of the fires have caused them to burn this time ${ }^{2}$.

As the fire season in Australia continues, what lessons have been learned and what are the next steps? First and foremost, the urgency of reducing emissions and reaching international climate agreements has been laid bare, and both the Australian government and others around the world need to pay heed. If for no other reason, the global shock and outrage over these fires means the days may be numbered for governments that conspicuously fail to act. At a more local level, we have to accept that fires of this intensity could become the new normal, and how we manage landscapes and human settlements will have to change. There is much that can be learned from nature about how to co-exist with fire, such as where to site buildings, how to protect them and what to construct them with ${ }^{3}$. Finally, as scientists, a detailed spatial examination will be needed of what ecosystems have burnt and which species have been affected, in order to model and mitigate future risk.

Published online: 22 January 2020 https://doi.org/10.1038/s41559-020-1119-4

\footnotetext{
References

1. Bowman, D. M. J. S. et al. Nat. Ecol. Evol. 1, 0058 (2017).

2. Smith, A. M. S., Kolden, C. A. \& Bowman, D. M. J. S. Nat. Ecol. Evol. 2, 1827-1829 (2018)

3. Nolan, R. H. et al. Glob. Change Biol. https://doi.org/10.1111/ gcb.14987 (2020).
} 